\title{
Examination of investment proposals for their inclusion in the infrastructure programs of the energy industry
}

\author{
Natalya Moiseenko ${ }^{1, *}$ and Olga Gorelova ${ }^{1}$ \\ ${ }^{1}$ State University of Management, Ryazanskiy prospect, 99, Moscow, 109542, Russia
}

\begin{abstract}
The paper discusses the key issues that allow finding approaches to solving the problem of investment activity in the process of developing and implementing investment projects and construction programs in the real sector of the economy. The mechanism of formation of investment programs is considered. The process of examination of investment projects for their inclusion in the investment program has been determined. The algorithm for making investment decisions is proposed.
\end{abstract}

\section{Introduction}

The investment program includes a set of organizational measures and can accumulate resource, production and other efforts of various organizations and departments for some time, specifies this in a system of interrelated measures, where production and economic measures are supported by organizational and economic measures. In a separate group, there are programs that are necessary for the regional and sectoral reproduction process: programs related to the formation, placement, efficient use of funds, savings and the integrated use of regional resources, nature conservation, social issues [1].

The main objective of the presented project management task, taking into account the formation of the investment program, is to try to develop the idea of alternative program management, for example, as a project with considerable value, having clearly defined resources, tasks, decision procedures, time, financial and other frameworks, implemented by a single focused project team and representing individual investment, social and other projects and activities, which is the project of reconstruction and technical re-equipment of operating enterprises. A major role in the specifics of building and implementing such a project is played by the level of its preparation, which should be significantly higher than for similar "internal" projects and more significant in relation to other structural and vital elements of the project management system. It is not only the results of its implementation that depend on the possibility of a successful and competent formation of the investment program [2].

\section{Materials and methods}

\footnotetext{
*Corresponding author: na_moiseenko@guu.ru
} 
At the stage of pre-investment study, a comprehensive description of measures should be applied to the selection of investment proposals. At the level of the investment program, this is the beginning of the mobilization of investment funds by supplying information about the newly discovered investment opportunities of potential investors. The purpose of such a set of measures is to draw attention to specific investment proposals and to transform the idea proved in the investment program into an investment proposal. Expert groups are created that examine the available investment proposals and review the available alternatives for the main components of the justification for certain criteria, including:

- investment opportunities are so promising that the decision to invest can be made on the basis of information obtained at the stage of preliminary justification;

- any aspects of the investment proposal are crucial for its efficiency and require indepth study through functional or auxiliary research;

- the available information is sufficient to determine whether the idea of an investment program is unviable or is it sufficiently attractive for a particular investor or group of investors;

- the state of the environment at the place of the intended location of the transport line.

Research in this area is carried out to study the existing roads and available access roads, including forecasting the growth of traffic flow in the region.

During the pre-investment stage, the possibilities of all investment proposals received under the investment program under consideration for each project included in its structure are being studied. The examination is carried out either by the customer's own efforts or by specialized consulting firms and studies alternative investment proposals, and also considers various investment decisions. The first stage ends with a final decision on the investment of the project, which was selected from the investment proposals offered to the expert council, which is accepted either by the customer, or by investors and financial institutions, and also a financing program is being drawn up.

To develop a sound investment proposal, it is necessary to carry out a reliable collection and analysis of the initial information for the investment proposal. The obtained information allows clarifying the concept of the investment proposal, preparing alternative options. Sources for the development of investment proposals may be available planning, pre-project materials, statistical and economic analysis of the state of affairs, the results of research, economic information, legislative acts, normative documents, orders of authorities at all levels $[3,4]$.

The correct analytical assessment of investment proposals can be obtained on the basis of their scientific classification. The used classification signs will be a tool for reflecting the order of examination of investment proposals within the implementation of investment projects as a stage to substantiate management decisions.

All investment projects before their approval are subject to examination in accordance with the legislation of the Russian Federation. Examination of all investment projects is carried out according to some general scheme, which includes special sections $[5,6]$.

The preliminary examination stage should not be long in time, and the conclusions that are drawn by experts at this stage are mainly based on qualitative assessments. Since the investment projects of road construction are carried out with already existing markets, an assessment of their commercial viability is needed, for which the project should have a marketing expertise. Based on the results of this expertise, the correctness of the choice of the strategy for the development of this road construction project, pricing, the degree of further use, as well as the prediction of the reaction of competitors and its subsequent impact on the ability to fulfill the marketing plan and future existence is assessed. Marketing expertise includes forecasting the future use and possible expansion of the transport line. 
The task of the technical examination of the investment project of road construction is to determine the technical condition of road construction, determine the technical condition of roads and justify their construction technologies, analyze local conditions, availability and cost of raw materials, energy, labor force, check the potential possibilities of planning and implementing the project. Technical examination is carried out by a group of own experts of the enterprise with the possible involvement of narrow specialists. The technology selection rule provides for a comprehensive examination of some alternative technologies and the selection of the best option on the basis of an aggregated criterion.

Financial examination of the investment project usually comes down to the calculation and interpretation of the basic financial ratios reflecting the liquidity, creditworthiness, profitability of the enterprise and the effectiveness of its management. It is important to compare the main indicators in the financial section by years.

Break-even examination is an analysis of the cost structure of the manufacture and sale of the main types of products and the division of all costs into variable and fixed. The main purpose of break-even analysis is to determine the break-even point. The most critical part of the financial division of the project is its investment part, which includes: determining the investment needs of the enterprise for the project, identifying sources of financing investment needs; assessment of the cost of capital raised for the implementation of the investment project; forecast of profits and cash flows due to project implementation; assessment of project performance indicators.

Institutional examination assesses the possibility of the investment project implementation, taking into account the organizational, legal, political, and administrative environment. Here, the main task of the experts is to assess the totality of internal and external factors. Assessment of internal factors means determination of the capabilities of production management. Due to the fact that road construction is characterized by specific features of the work and the relationship between personnel, it is important to assess the experience and qualifications of managers of the enterprise, their motivation within the project.

Special importance is attached to the issues of examination of risks in the justification and implementation of investment projects. This is due to the unsteady market relations and insufficient training of specialists to carry out work in this field of activity.

The essence of the examination of investment proposals in the framework of the investment program on the part of a potential investor is the averaging of the opinions of expert specialists on the significant priorities of the selection of investment proposals. During the examination of investment proposals, assessment, diagnostic and search functions are consistently implemented. The assessment function of the examination allows comparing the final results of the investment proposal examination with predetermined parameters and assessing its compliance with the analyzed investment program. The diagnostic examination function is aimed at recognizing the state of the investment proposal being studied. The implementation of this function depends on the correct choice of examination methods, as well as the ability of experts to recognize the decisive factors that reflect the specific possibilities for increasing the efficiency of the investment proposal of the investment program under consideration. The final stage of the investment proposal examination is the implementation of the search function, which provides not only the calculation of the selected decisive criteria but also the preparation of recommendations for improving the indicators of the investment proposal $[7,8]$.

To select options for the proposal and decide on its implementation, it is necessary to use informal expert procedures to take into account the significance of all factors and their interrelations. Therefore, a potential investor should define its own system of priorities: the compliance of the investment proposal with the tasks of the investment program. 


\section{Results}

The investment proposal requires a substantiation of the interests of each investor. This may be receiving interest on invested funds or converting them into shares, purchasing preferred shares, including convertible into ordinary shares, equity investments, purchasing a nominal block of shares with subsequent capitalization of investments. There can be a mixed investment, when opportunities and the number of partners of interested related sectors or individual investor enterprises are assessed to be able to finance the project as a co-investor. It is necessary to take into account the specifics of the industry and the specifics of the investment program. Thus, in the investment programs of road construction, in addition to the generally accepted components, serious attention should be paid to the improvement of the roadside infrastructure, in the construction of which various investors participate. Infrastructure objects undoubtedly increase the load on the roadbed, increase the volume of cargo traffic and traffic flows. Therefore, share participation of such investors is necessary in the general investment program aimed at building and repairing roads in this particular region or municipal entity. Such a share participation, in our opinion, can be organized by creating a special fund - the "Encumbrance fund", which is formed from the deduction of co-investors or equity partners of the subprogram. Infrastructure facilities can be divided into three groups: the objects of technical and consumer services, objects of relevant assignments, and objects of production purpose. The first group includes recreation areas for drivers, vehicle maintenance companies, service centers, areas for long parking of transport, etc. The second group includes shops, cafes, hypermarkets with parking lots, dealerships for selling cars and spare parts, and etc. The third group includes warehouses and terminals for storage and reloading of cargoes to other types of transport, production workshops, repair shops, etc. The amount of income to the encumbrance fund can be determined by the following formula:

$$
\mathrm{F}=\mathrm{C} * \Sigma \mathrm{k}_{\mathrm{i}}
$$

where: $\mathrm{F}$ - the amount of income to the encumbrance fund; $\mathrm{C}$ - the estimated cost of the infrastructure facility; $\Sigma \mathrm{k}_{\mathrm{i}}$ - the sum of the factors that increase the load on the road.

Such factors include the percentage of increase in freight turnover, the percentage of increase in transport units passing by the road per unit of time from public transport, private transport, cargo transport, the percentage of the increase in load on the roadbed, etc. The composition and value of the factors are taken depending on the specific construction project and can be calculated either on the basis of technical characteristics or on the basis of expert estimates.

Correct construction of an analytical assessment of investment proposals can be obtained on the basis of their scientific classification, while the classification criteria used are a tool for reflecting the procedure for conducting an examination of investment proposals within the framework of implementation of investment projects and the investment program as a stage of substantiation of management decisions.

All investment projects, regardless of the sources of financing and ownership of capital investment objects, prior to their approval, are subject to examination in accordance with the legislation of the Russian Federation. Examination of investment projects is carried out in order to prevent the creation of objects, the use of which violates the rights of individuals and legal entities and the interests of the state or does not meet the requirements of standards approved in the prescribed manner, as well as to assess the efficiency of capital investments. 
Preliminary examination can be carried out by groups of proposals. For the minimum listing, it is advisable to distinguish the following groups of sentences:

- proposals received from an investor who wants to invest free funds profitably;

- investment proposals received from an investor who wants to participate in the implementation of the investment program with his own assets.

The main tool of preliminary examination is the usual method of expert assessments. For the examination, the list of criteria in the form of questionnaires for experts is developed. Each criterion is given an appropriate weighting factor, depending on its importance.

Depending on the assessment, the proposal may be rejected, sent for revision, transferred for in-depth examination, transferred to the decision-making stage. (Fig. 1)

The selection of investment proposals can be made on a competitive basis. The organizers of the examination must first assess the significance of individual criteria, either by listing priority characteristics or by setting weighting factors for each criterion. It is more convenient to carry out a formalized examination procedure on the basis of a standard questionnaire filled in by experts. The same questionnaires can serve as a guideline for the developers of the investment proposal when filling in the relevant sections.

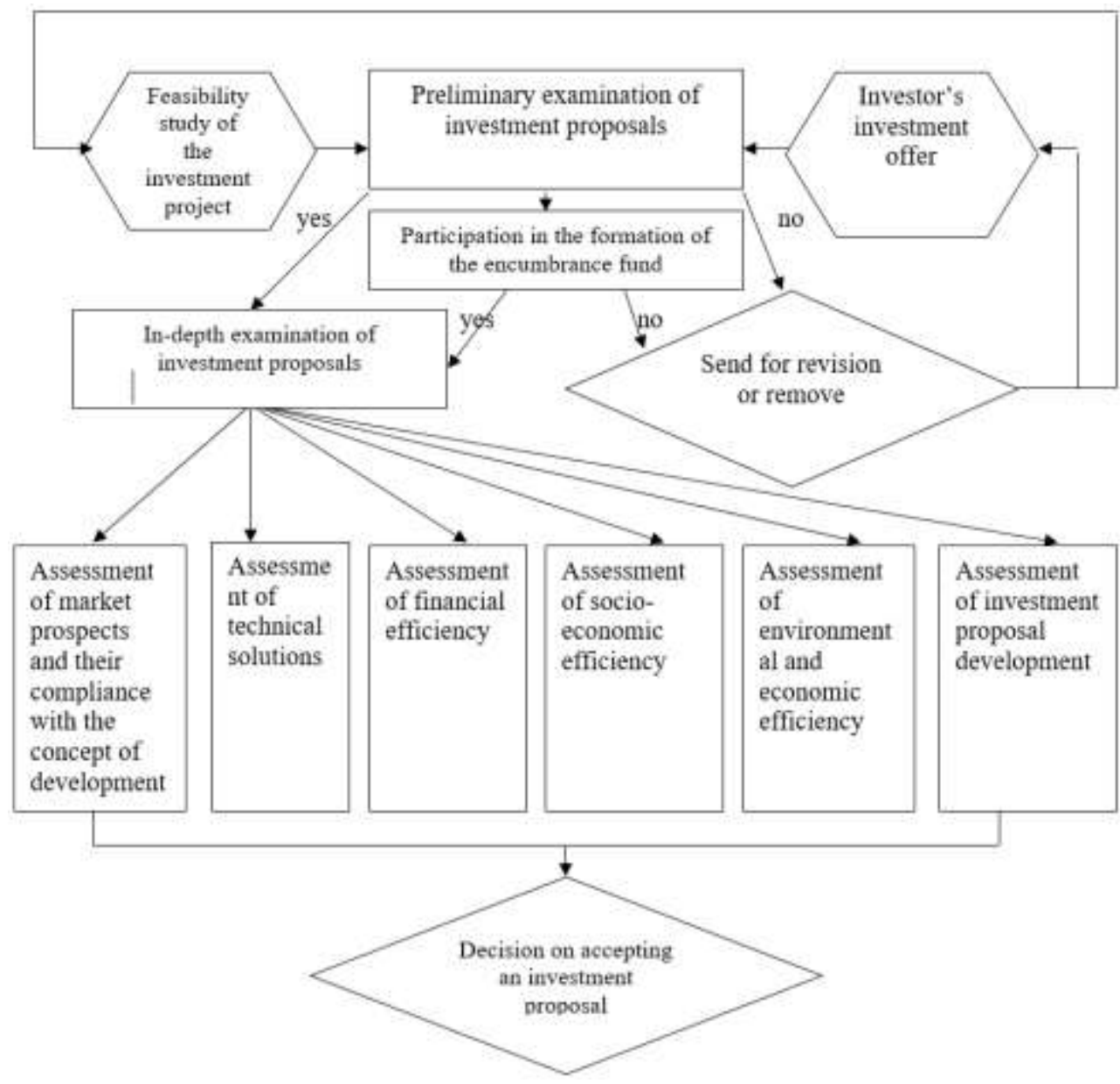

Fig.1. Algorithm for the examination of received investment proposals. 
The selection of proposals cannot be made on the basis of one criterion. The decision should be made on the basis of the integral efficiency indicator, which takes into account a number of characteristics of the proposal and is its rating. To calculate this indicator and select the most effective investment proposals, a number of organizational measures should be carried out.

For the assessment and selection of proposals, mathematical models are used to determine the best option from the proposals under consideration. The investment process is determined by the influence of various factors that cannot always be expressed quantitatively. The qualitative nature of factors that are important to the proposal limits the use of mathematical methods and strengthens the role of an expert in decision making. Preliminary examination is characterized by the possibility of obtaining an integral indicator of the efficiency of the proposal on the basis of the results of the analysis carried out by several experts, which will make it possible to compare the offers among themselves.

\section{Conclusion}

In the process of in-depth examination, validation of the data used, the calculation of the indicators of investment efficiency, the efficiency of the production activity of the enterprise and its financial condition, and the analysis of the sensitivity of the proposal for various scenarios is carried out. For each of the proposals, several variants of calculations are made with different sets of input data reflecting the best and worst conditions for the development of the proposal. In-depth examination should take into account the dynamics of market, technological, innovation and other trends both observable and predictable in the Russian economy. The results of the in-depth examination are transferred for making a final decision on the formation of a list of investment proposals for inclusion in the investment program.

\section{References}

1. A.N. Asaul, D.A. Zavarin, S.N. Ivanov, Fundamental'nyye issledovaniya 4-0, 180-184 (2015)

2. N.P. Makarkin, Effektivnost' real'nykh investitsiy, Uchebnoye posobiye (INFRA-M, Moscow, 2011)

3. Ye.M. Petrikova, Finance and credit 25, 40-44 (2011)

4. N.V. Samosudova, A.D. Cherkas, Modern innovations 2(2), 30-32 (2015)

5. V.M. Serov, Buildertion. Economics and Management 2(24), 10-17 (2017)

6. Y.P. Tikhonov, Construction Economics 4(52), 52-60 (2018)

7. R. Golov, T. Narezhnaya, N. Voytolovskiy, V. Mylnik, E. Zubeeva, MATEC Web of Conferences (2018) https://doi.org/10.1051/matecconf/201819305080

8. I. Lukmanova, R. Golov, E3S Web of Conferences (2018) https://doi.org/10.1051/e3sconf/20183302047 